\title{
2.4 GHz CMOS Power Amplifier with Mode-Locking Structure to Enhance Gain
}

\author{
Changhyun Lee and Changkun Park \\ School of Electronic Engineering, College of Information Technology, Soongsil University, 551 Sangdo-Dong, Dongjak-Gu, \\ Seoul 156-743, Republic of Korea \\ Correspondence should be addressed to Changkun Park; pck77@ssu.ac.kr
}

Received 29 January 2014; Accepted 4 June 2014; Published 17 June 2014

Academic Editor: Noel Rodriguez

Copyright (C) 2014 C. Lee and C. Park. This is an open access article distributed under the Creative Commons Attribution License, which permits unrestricted use, distribution, and reproduction in any medium, provided the original work is properly cited.

\begin{abstract}
We propose a mode-locking method optimized for the cascode structure of an RF CMOS power amplifier. To maximize the advantage of the typical mode-locking method in the cascode structure, the input of the cross-coupled transistor is modified from that of a typical mode-locking structure. To prove the feasibility of the proposed structure, we designed a $2.4 \mathrm{GHz}$ CMOS power amplifier with a $0.18 \mu \mathrm{m}$ RFCMOS process for polar transmitter applications. The measured power added efficiency is $34.9 \%$, while the saturated output power is $23.32 \mathrm{dBm}$. The designed chip size is $1.4 \times 0.6 \mathrm{~mm}^{2}$.
\end{abstract}

\section{Introduction}

Currently, CMOS (complementary metal-oxide semiconductor) devices are the most popular for RFIC (radio frequency integrated circuit) design due to their low cost [1-15]. In particular, CMOS RFICs can more easily be integrated with other analog or digital ICs than with GaAS (gallium arsenide) RFICs [16-21]. Although GaAs devices are regarded as more suitable than CMOS ones, there have been vigorous studies about how to reduce unit costs of CMOS power amplifiers [22-27]. If a successful CMOS power amplifier is developed, the potential for creating a fully integrated, frontend IC should increase. Nevertheless, compared to those using GaAs, CMOS power amplifiers still have drawbacks, including (1) low breakdown voltage, (2) lossy substrate, (3) low linearity, and (4) low gain. The issues related to the breakdown voltage and substrate loss have been successfully investigated and resolved using the distributed active transformer (DAT) proposed by Aoki et al. [22]. Additionally, techniques to solve the low-linearity problem of CMOS power amplifiers have also been intensively studied, and some successful techniques have been introduced [28-31].

Regarding the issue of low gain of CMOS power amplifiers, the mode-locking technique is one of the most successful solutions [32]. Accordingly, the concepts of the modelocking technique have been vigorously adapted in previous work. In this study, we also focused on the improvement of gain of the CMOS power amplifier. While the modelocking technique was adapted to a common-source amplifier in previous work, here, we propose a method for the modelocking technique to be adapted to the cascode structure. The cascode structure is essential to overcome the low breakdown voltage problems of CMOS devices. To prove the feasibility of the proposed structure, we designed a $2.4 \mathrm{GHz} \mathrm{CMOS}$ power amplifier using the proposed structure.

\section{Typical Mode-Locking Technique}

Figure 1 provides examples of CMOS power amplifiers using typical mode-locking technique. The structure shown in Figure 1(a) is the primary structure of the amplifier using the mode-locking technique. In Figure 1 , for the sake of simplicity, the switch to control the oscillation is omitted. As shown in Figure 1(a), the differential structure is essential to adapt the mode-locking technique. Moreover, the differential structure provides an advantage for generating a virtual ground node and hence for minimizing the gainreduction problems induced by the bond wires. As can be seen in Figure 1(a), the cross-coupled transistors $\left(M_{\mathrm{CC}}\right)$ were used to construct the mode-locking structure. Although the input signal enters through the gate of the common-source transistors $\left(M_{\mathrm{CS}}\right)$, the $M_{\mathrm{CC}}$ also acts as the amplifier stage. 


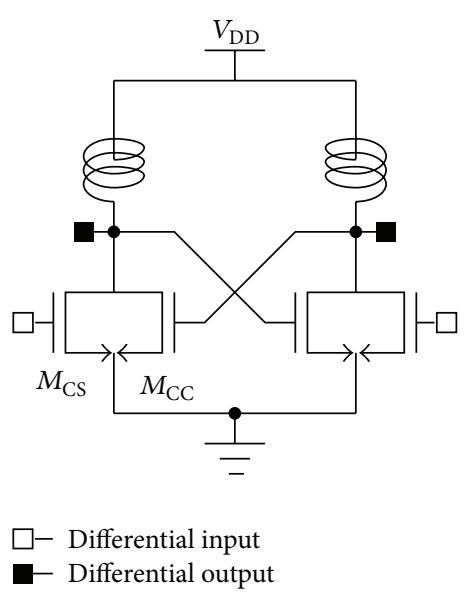

(a)

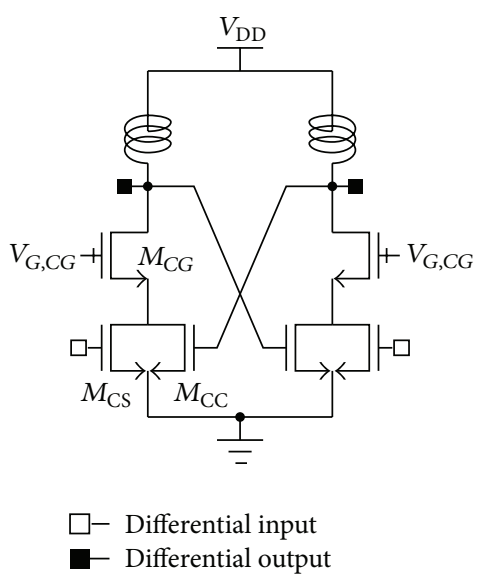

(b)

FIGURE 1: CMOS power amplifiers using mode-locking technique: (a) typical and (b) modified structures.

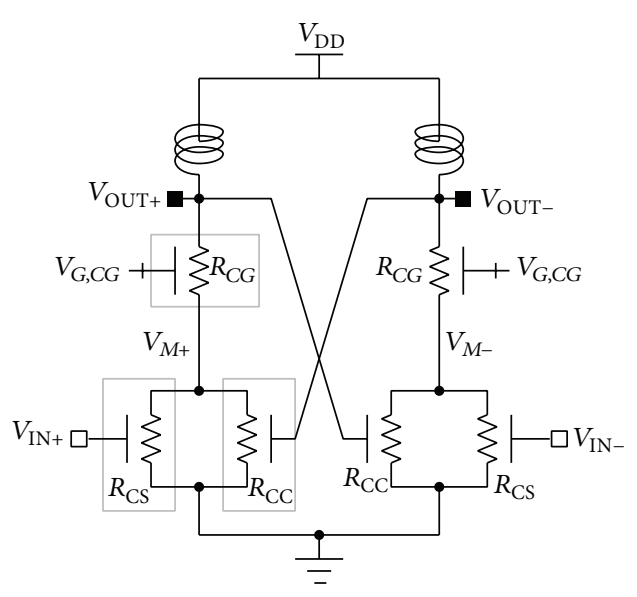

FIGURE 2: Simple equivalent circuit of cascode structure with modelocking method.

Accordingly, the mode-locking structure can elevate the gain as compared to a typical common-source amplifier.

Recently, as the CMOS technology has been scaled down, the cascode structure has become the most commonly used one for CMOS power amplifiers, to moderate breakdown voltage problems. Figure 1(b) shows the cascode structure adapted for the mode-locking technique. In Figure 1, the drain voltage of $M_{C G}$ is used as the input of $M_{\mathrm{CC}}$. In a previous work [33], to moderate the excessive voltage swing of input of $M_{\mathrm{CC}}$, the series capacitor was inserted between the drain of $M_{C G}$ and the gate of $M_{\mathrm{CC}}$. However, the conceptual operation principle presented in Figure 1(b) is identical to that in Figure 1(a).

\section{Proposed Mode-Locking Method with the Cascode Structure}

Although the feasibility of the mode-locking technique merged into the cascode structure was successfully proven

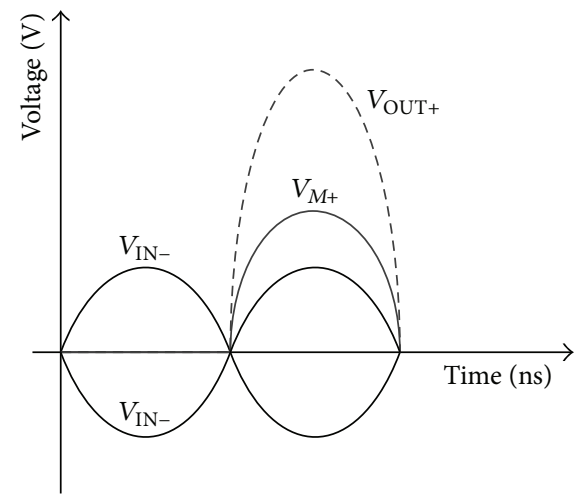

FIGURE 3: Ideal voltage waveforms of the cascode structure with mode-locking method.

in previous work [33], the time delay between input of $M_{\mathrm{CS}}$ and input of $M_{\mathrm{CC}}$ of the structure shown in Figure 1(b) may obstruct maximization of the advantages of the mode-locking technique. To investigate the time delay problems indicated in Figure 1(b), we simplified the structure shown there with on-resistances as shown in Figure 2. In Figure 2, $R_{\mathrm{CS}}, R_{C G}$, and $R_{\mathrm{CC}}$ denote the on-resistances of $M_{\mathrm{CS}}, M_{\mathrm{CG}}$, and $M_{\mathrm{CC}}$, respectively. If the time delay between $V_{\mathrm{IN}+}$ (or $\left.V_{\mathrm{IN}-}\right)$ and $V_{M+}$ (or $V_{M_{-}}$) is $t_{\mathrm{CS}}$, the time delay, $t_{\mathrm{CC}}$, between $V_{\mathrm{IN}+}\left(\right.$ or $\left.V_{\mathrm{IN}-}\right)$ and $V_{\text {OUT+ }}\left(\right.$ or $V_{\text {OUT- }}$ ) can then be calculated as follows:

$$
t_{\mathrm{CC}} \approx t_{\mathrm{CS}}+5 \tau \quad\left(\tau=R_{\mathrm{CG}} C_{\mathrm{OUT}}\right) .
$$

Here, $C_{\text {OUT }}$ is the equivalent capacitance at $V_{\text {OUT }}$ or

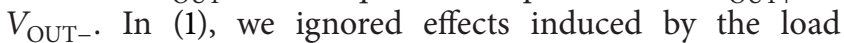
impedances connected to $V_{\text {OUT+ }}$ and $V_{\text {OUT-- If the effects }}$ of load impedances are considered, the time constant, $\tau$, increases. Additionally, we assumed that the $C_{\text {OUT }}$ is fully discharged or charged after five time constants. Figure 3 provides the ideal voltage waveforms of the device in Figure 2.

Given that $M_{\mathrm{CC}}$ should perform the identical function of the $M_{\mathrm{CS}}$ in general, the value of $t_{\mathrm{CC}}$ needs to be minimized 


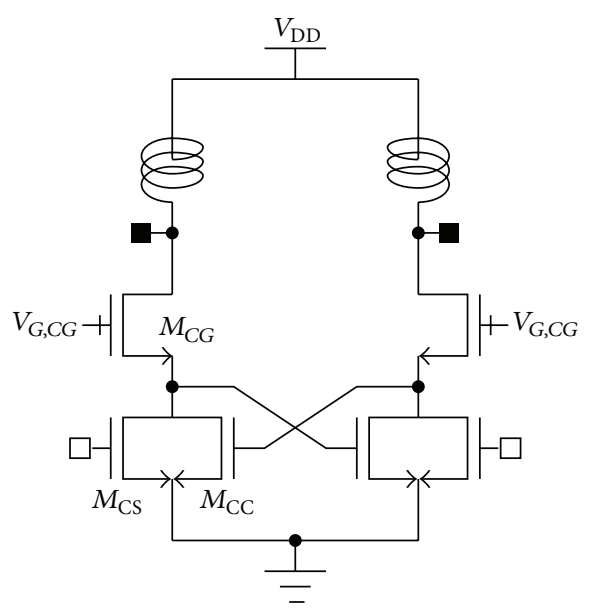

FIGURE 4: Proposed mode-locking technique for the cascode structure.

to maximize the advantage of the mode-locking technique. Undesired, excessive time delay, $t_{\mathrm{CC}}$, may cause the undesired effects, even harmonics. Additionally, the excessive value of $t_{\mathrm{CC}}$ may prevent switching conditions that would be ideal for high efficiency of the switching-mode power amplifier.

Here, we proposed a modified, mode-locking technique for the cascode structure to minimize the time delay, $t_{\mathrm{CC}}$ of (1). In the proposed structure (Figure 4), the input of the $M_{\mathrm{CC}}$ is connected to the drain of $M_{\mathrm{CS}}$. The time delay between input of $M_{\mathrm{CS}}$ and input of $M_{\mathrm{CC}}$ is reduced to $t_{\mathrm{CS}}$.

Compared to the typical structure shown in Figure 1(b), the time delay is reduced with amount of $5 \tau$ of (1). Although the time delay, $t_{\mathrm{CS}}$, still exists, the undesired effects induced by the excessive time delay may be minimized with the proposed structure.

\section{Experimental Results: Design and Measured Results of 2.4 GHz CMOS Power Amplifier with Proposed Mode-Locking Technique}

To verify the feasibility of the proposed structure, we designed a $2.4 \mathrm{GHz}$ power amplifier using $0.18 \mu \mathrm{m}$ RF CMOS technology with one poly, and six metal layers. Top metal layer was composed of aluminum $2.3 \mu \mathrm{m}$ thick. The power amplifier is designed as switching mode amplifier for polar transmitter, or sensor network, applications. All of the input and output matching networks are fully integrated, including test PADs and transformers. Important design parameters, including the transistor size, are provided in Figure 5. The input and output transformer were designed using an electromagnetic simulator. To minimize the loss induced by the resistance of the output transformer, the width of the output transformer is wider than that of the input transformer. The supply voltage of the amplifier enters through the center tap of the primary part of the output transformer. To minimize the gain reduction problems induced by the bond wires, a differential structure was adapted. All of the resistors for the bias are $2 \mathrm{k} \Omega$. Figure 6

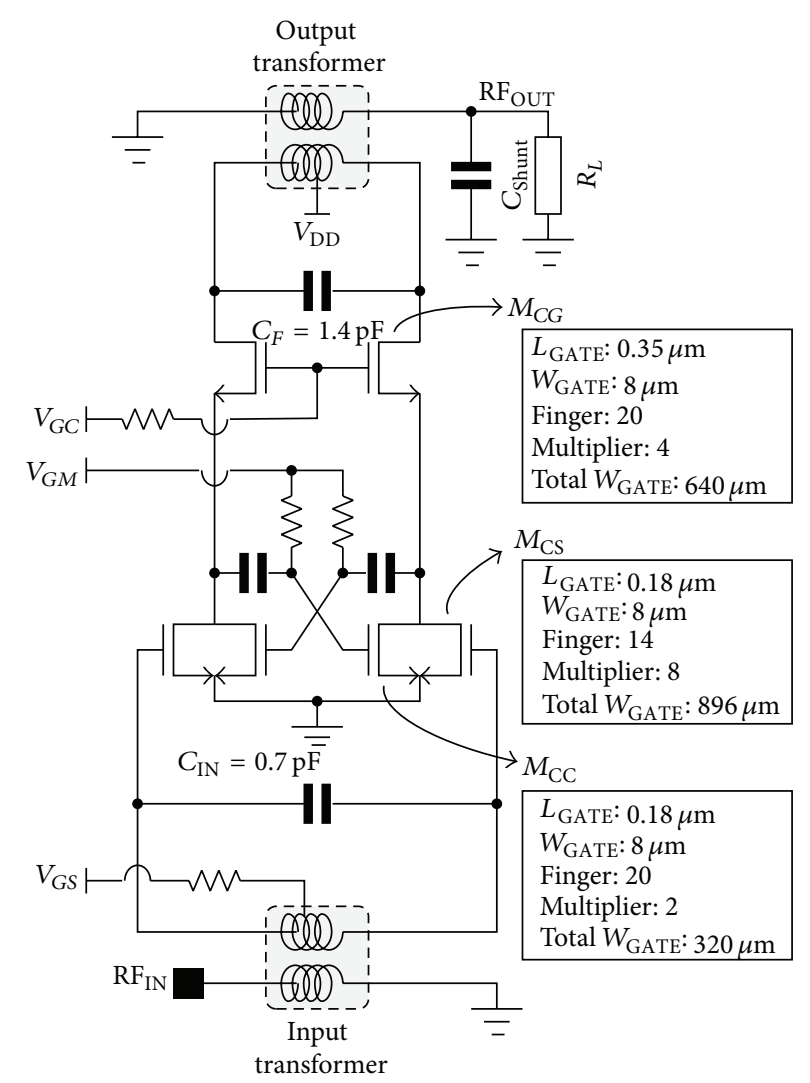

FIGURE 5: Schematic of the proposed power amplifier.

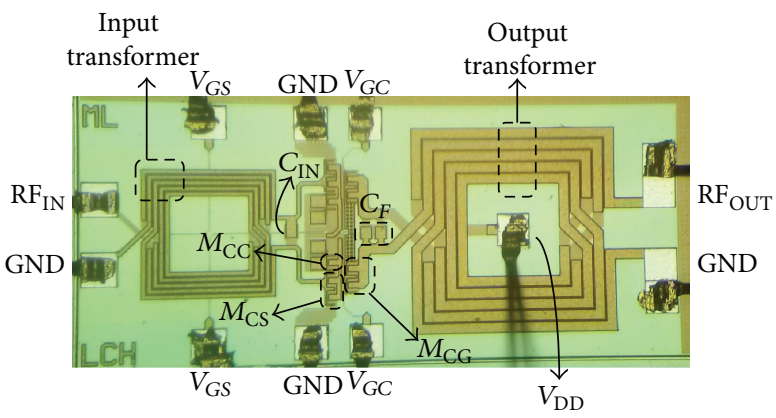

Figure 6: Photograph of the newly designed power amplifier.

shows the chip photograph of the newly designed power amplifier. The chip size is $1.4 \times 0.6 \mathrm{~mm}^{2}$.

Figure 7 shows the measured output power and power added efficiency (PAE), according to the operating frequency, with a fixed supply voltage $\left(V_{\mathrm{DD}}\right)$ of $3.3 \mathrm{~V}$. As provided in Figure 7, the output power and PAE at $2.4 \mathrm{GHz}$ were $23.32 \mathrm{dBm}$ and $34.9 \%$, respectively. Figure 8 shows the PAE versus the output power according to $V_{\mathrm{DD}}$ ranging from $0.5 \mathrm{~V}$ to $3.3 \mathrm{~V}$.

\section{Conclusions}

In this study, we proposed a mode-locking technique for a cascode CMOS power amplifier. Using the drain voltage of 


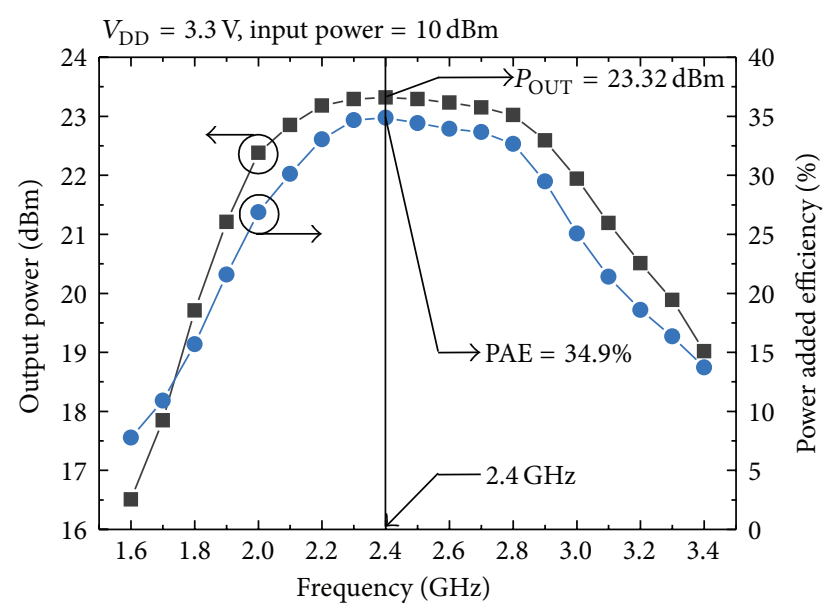

FIGURE 7: Measured output power and efficiency according to operating frequency.

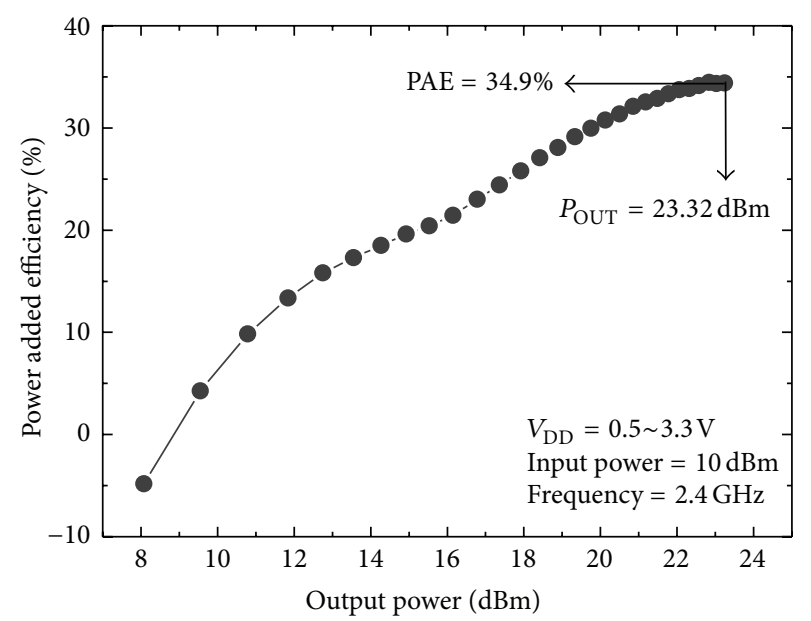

FIGURE 8: Measured output power and efficiency according to supply voltage.

a common-source transistor as the input of the cross-coupled transistor, the time delay between the common-source and cross-coupled transistors was minimized to maximize the advantage of the mode-locking technique. To prove the feasibility of the proposed technique, we designed a $2.4 \mathrm{GHz}$ CMOS power amplifier with a $0.18 \mu \mathrm{m}$ RFCMOS process for polar transmitter applications. The measured power added efficiency is $34.9 \%$, while the saturated output power is $23.32 \mathrm{dBm}$. The size of the newly designed chip was $1.4 \times$ $0.6 \mathrm{~mm}^{2}$.

\section{Conflict of Interests}

The authors declare that there is no conflict of interests regarding the publication of this paper.

\section{Acknowledgment}

This work was supported by the Basic Science Research Program through the National Research Foundation of Korea (NRF) funded by the Ministry of Education, Science and Technology (2012-044627).

\section{References}

[1] J.-N. Chang and Y.-S. Lin, "A high-performance CMOS power amplifier for $60 \mathrm{GHz}$ short-range communication systems," Microwave and Optical Technology Letters, vol. 55, no. 5, pp. 1155-1160, 2013.

[2] J. Oh, H. Kim, M.-S. Kim et al., "Integrated CMOS RF transmitter with a single-ended power amplifier," Microwave and Optical Technology Letters, vol. 55, no. 1, pp. 205-210, 2013.

[3] J. Kong and J. Jeong, "Linearization of stacked-FET RF CMOS power amplifier using diode-integrated bias circuit," Microwave and Optical Technology Letters, vol. 55, no. 5, pp. 1011-1014, 2013.

[4] J. Oh, B. Ku, and S. Hong, "A 77-GHz CMOS power amplifier with a parallel power combiner based on transmission-line transformer," IEEE Transactions on Microwave Theory and Techniques, vol. 61, no. 7, pp. 2662-2669, 2013.

[5] K. Yousef, H. Jia, R. Pokharel et al., "CMOS ultra-wideband low noise amplifier design," International Journal of Microwave Science and Technology, vol. 2013, Article ID 328406, 6 pages, 2013.

[6] B. Koo, Y. Na, and S. Hong, "Integrated bias circuits of RF CMOS cascode power amplifier for linearity enhancement," IEEE Transactions on Microwave Theory and Techniques, vol. 60, no. 2, pp. 340-351, 2012.

[7] M. Voicu, D. Pepe, and D. Zito, "Performance and trends in millimetre-wave CMOS oscillators for emerging wireless applications," International Journal of Microwave Science and Technology, vol. 2013, Article ID 312618, 6 pages, 2013.

[8] S.-Y. Lee, H. Ito, S. Amakawa, N. Ishihara, and K. Masu, "An inductorless cascaded phase-locked loop with pulse injection locking technique in $90 \mathrm{~nm}$ CMOS," International Journal of Microwave Science and Technology, vol. 2013, Article ID 584341, 11 pages, 2013.

[9] C. Park, J. Han, H. Kim, and S. Hong, "A 1.8-GHz CMOS power amplifier using a dual-primary transformer with improved efficiency in the low power region," IEEE Transactions on Microwave Theory and Techniques, vol. 56, no. 4, pp. 782-792, 2008.

[10] C. Park, Y. Kim, H. Kim, and S. Hong, "A 1.9-GHz triple-mode class-E power amplifier for a polar transmitter," IEEE Microwave and Wireless Components Letters, vol. 17, no. 2, pp. 148-150, 2007.

[11] W. Tangsrirat, " $\mathrm{G}_{\mathrm{m}}$-realization of controlled-gain current follower transconductance amplifier," The Scientific World Journal, vol. 2013, Article ID 201565, 8 pages, 2013.

[12] J. Jalil, M. B. I. Reaz, M. A. S. Bhuiyan, L. F. Rahman, and T. G. Chang, "Designing a ring-VCO for RFID transponders in $0.18 \mu \mathrm{m}$ CMOS process," The Scientific World Journal, vol. 2014, Article ID 580385, 6 pages, 2014.

[13] F. Tang, A. Bermak, A. Amira, M. A. Benamar, D. He, and X. Zhao, "Two-step single slope/SAR ADC with error correction for CMOS image sensor," The Scientific World Journal, vol. 2014, Article ID 861278, 6 pages, 2014.

[14] H. Aljarajreh, M. B. I. Reaz, M. S. Amin, and H. Husain, "An active inductor based low noise amplifier for RF receive," Elektronika ir Elektrotechnika, vol. 19, no. 5, pp. 49-52, 2013. 
[15] I. Guerra-Gomez and E. Tlelo-Cuautle, "Sizing analog integrated circuits by current-branches-bias assignments with heuristics," Elektronika ir Elektrotechnika, vol. 19, no. 10, pp. 8186, 2013.

[16] Y. Lee and S. Hong, "A dual-power-mode output matching network for digitally modulated CMOS power amplifier," IEEE Transactions on Microwave Theory and Techniques, vol. 61, no. 4, pp. 1570-1579, 2013.

[17] J. Kim, D. Kim, Y. Cho, D. Kang, B. Park, and B. Kim, "Envelope-tracking two-stage power amplifier with dual-mode supply modulator for LTE applications," IEEE Transactions on Microwave Theory and Techniques, vol. 61, no. 1, pp. 543-552, 2013.

[18] K. Y. Kao, Y. C. Hsu, K. W. Chen, and K. Y. Lin, "Phase-delay cold-FET pre-distortion linearizer for millimeter-wave CMOS power amplifiers," IEEE Transactions on Microwave Theory and Techniques, vol. 61, no. 12, pp. 4505-4519, 2013.

[19] A. F. Aref and R. Negra, "A fully integrated adaptive multiband multimode switching-mode CMOS power amplifier," IEEE Transactions on Microwave Theory and Techniques, vol. 60, no. 8, pp. 2549-2561, 2012.

[20] K. Y. Son, B. Koo, and S. Hong, "A CMOS power amplifier with a built-in RF predistorter for handset applications," IEEE Transactions on Microwave Theory and Techniques, vol. 60, no. 8, pp. 2571-2580, 2012.

[21] S. Aloui, B. Leite, N. Demirel, R. Plana, D. Belot, and E. Kerherve, "High-gain and linear $60-\mathrm{GHz}$ power amplifier with a thin digital 65-nm CMOS technology," IEEE Transactions on Microwave Theory and Techniques, vol. 61, no. 6, pp. 2425-2437, 2013.

[22] I. Aoki, S. D. Kee, D. B. Rutledge, and A. Hajimiri, "Distributed active transformer-a new power-combining and impedancetransformation technique," IEEE Transactions on Microwave Theory and Techniques, vol. 50, no. 1, pp. 316-331, 2002.

[23] J. Park, C. Lee, and C. Park, "A brief review: stage-convertible power amplifier using differential line inductor," Wireless Engineering and Technology, vol. 3, no. 4, pp. 189-194, 2012.

[24] T. Joo, H. Lee, S. Shim, and S. Hong, "CMOS RF power amplifier for UHF stationary RFID reader," IEEE Microwave and Wireless Components Letters, vol. 20, no. 2, pp. 106-108, 2010.

[25] S. J. Wilk, W. Lepkowski, and T. J. Thornton, " $32 \mathrm{dBm}$ power amplifier on $45 \mathrm{~nm}$ SOI CMOS," IEEE Microwave and Wireless Components Letters, vol. 23, no. 3, pp. 161-163, 2013.

[26] J. H. Chen, S. R. Helmi, A. Y. S. Jou, and S. Mohammadi, "A wideband power amplifier in $45 \mathrm{~nm}$ CMOS SOI technology for X-Band applications," IEEE Microwave and Wireless Components Letters, vol. 23, no. 11, pp. 587-589, 2013.

[27] J.-H. Chen, S. R. Helmi, H. Pajouhi, Y. Sim, and S. Mohammadi, "A wideband RF power amplifier in 45-nm CMOS SOI technology with substrate transferred to AlN," IEEE Transactions on Microwave Theory and Techniques, vol. 60, no. 12, pp. 40894096, 2012.

[28] H.-Y. Chung, C.-W. Kuo, and H.-K. Chiou, "A full X-band power amplifier with an integrated guanella-type transformer and a predistortion linearizer in 0.18- $\mu \mathrm{M}$ CMOS," Microwave and Optical Technology Letters, vol. 55, no. 9, pp. 2229-2232, 2013.

[29] K. Kwon and I. Nam, "A linearization technique for a transconductor using vertical bipolar junction transistors in a CMOS process," IEEE Transactions on Microwave Theory and Techniques, vol. 61, no. 1, pp. 195-203, 2013.
[30] B. François and P. Reynaert, "A fully integrated watt-level linear 900-MHz CMOS RF power amplifier for LTE-applications," IEEE Transactions on Microwave Theory and Techniques, vol. 60, no. 6, pp. 1878-1885, 2012.

[31] D. Chowdhury, C. D. Hull, O. B. Degani, Y. Wang, and A. M. Niknejad, "A fully integrated dual-mode highly linear $2.4 \mathrm{GHz}$ CMOS power amplifier for $4 \mathrm{G}$ WiMax applications," IEEE Journal of Solid-State Circuits, vol. 44, no. 12, pp. 3393-3402, 2009.

[32] K.-C. Tsai and P. R. Gray, "A 1.9-GHz, 1-W CMOS class-E power amplifier for wireless communications," IEEE Journal of SolidState Circuits, vol. 34, no. 7, pp. 962-970, 1999.

[33] C. Lee, J. Park, and C. Park, "X-band CMOS power amplifier using mode-locking method for sensor applications," Journal of Electromagnetic Waves and Applications, vol. 26, no. 5-6, pp. 633-640, 2012. 

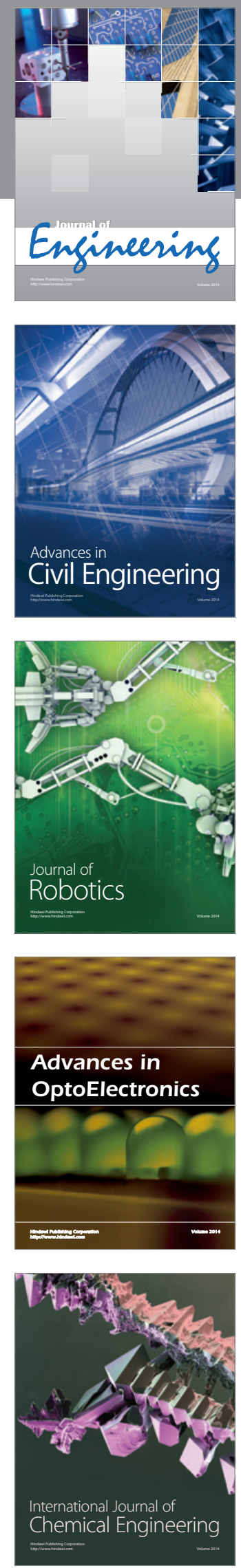

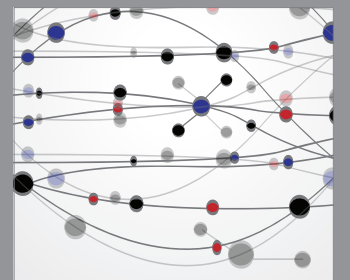

The Scientific World Journal
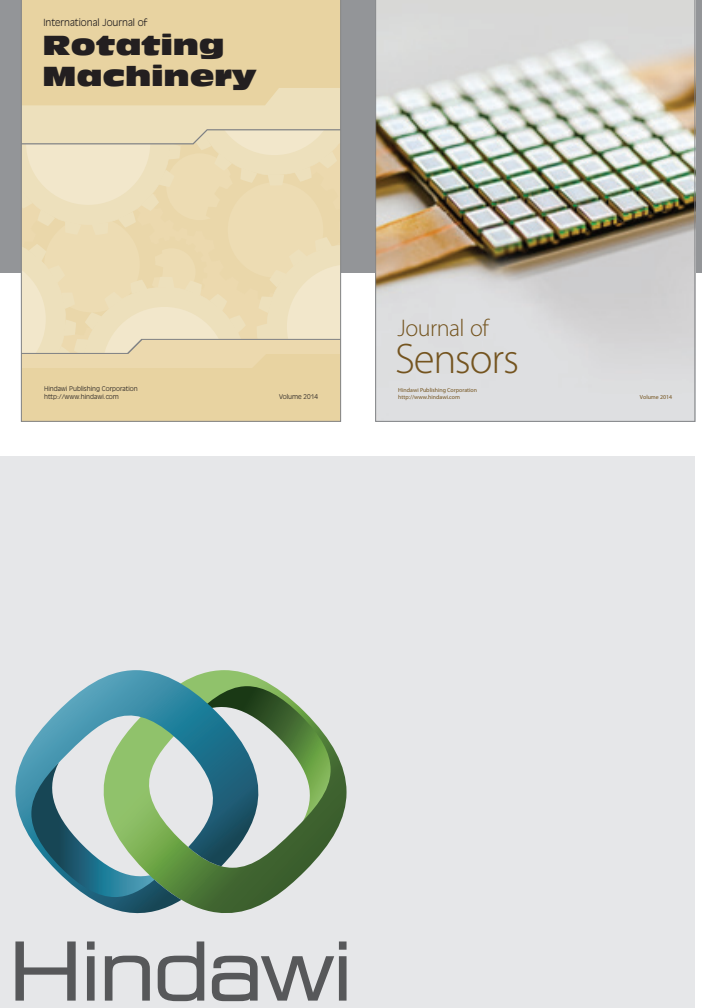

Submit your manuscripts at http://www.hindawi.com
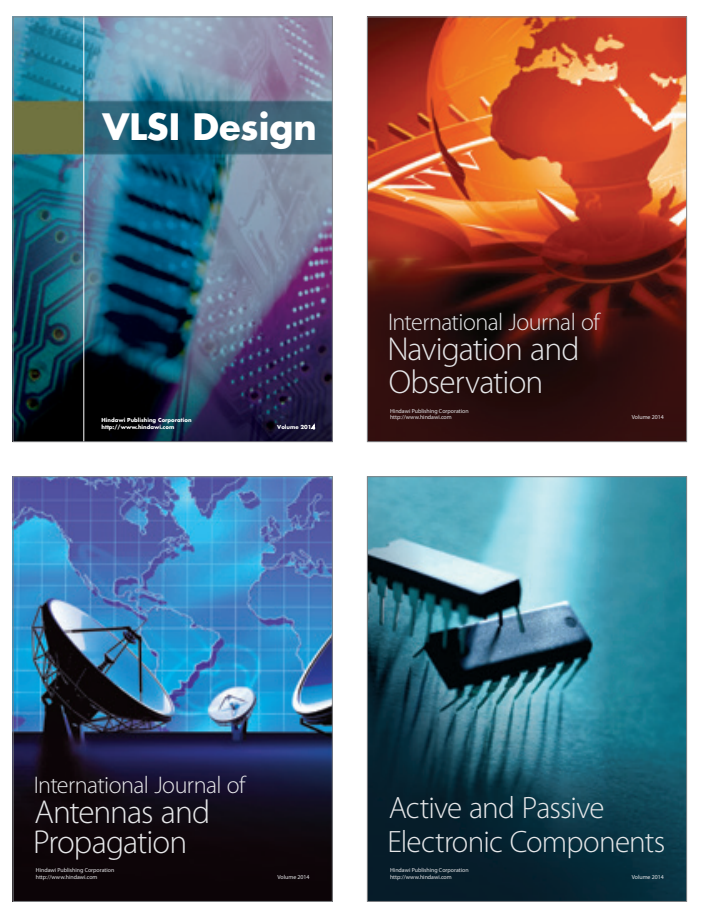
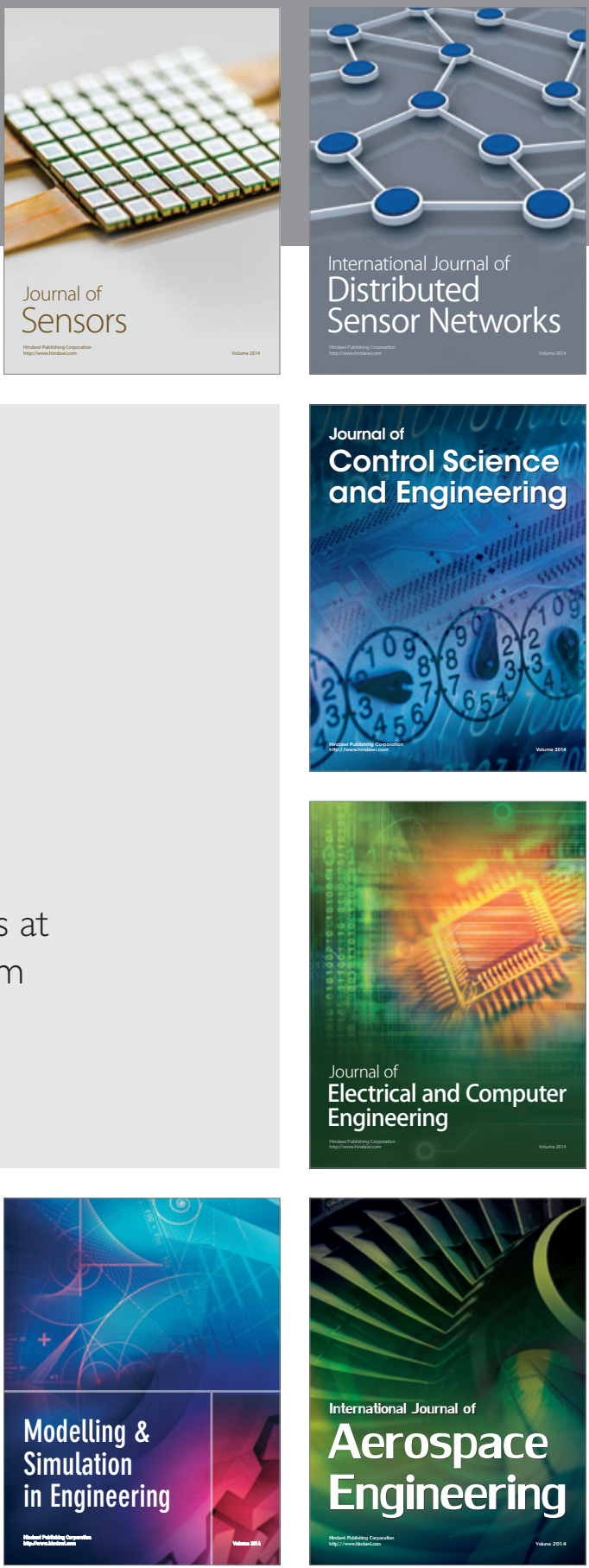

Journal of

Control Science

and Engineering
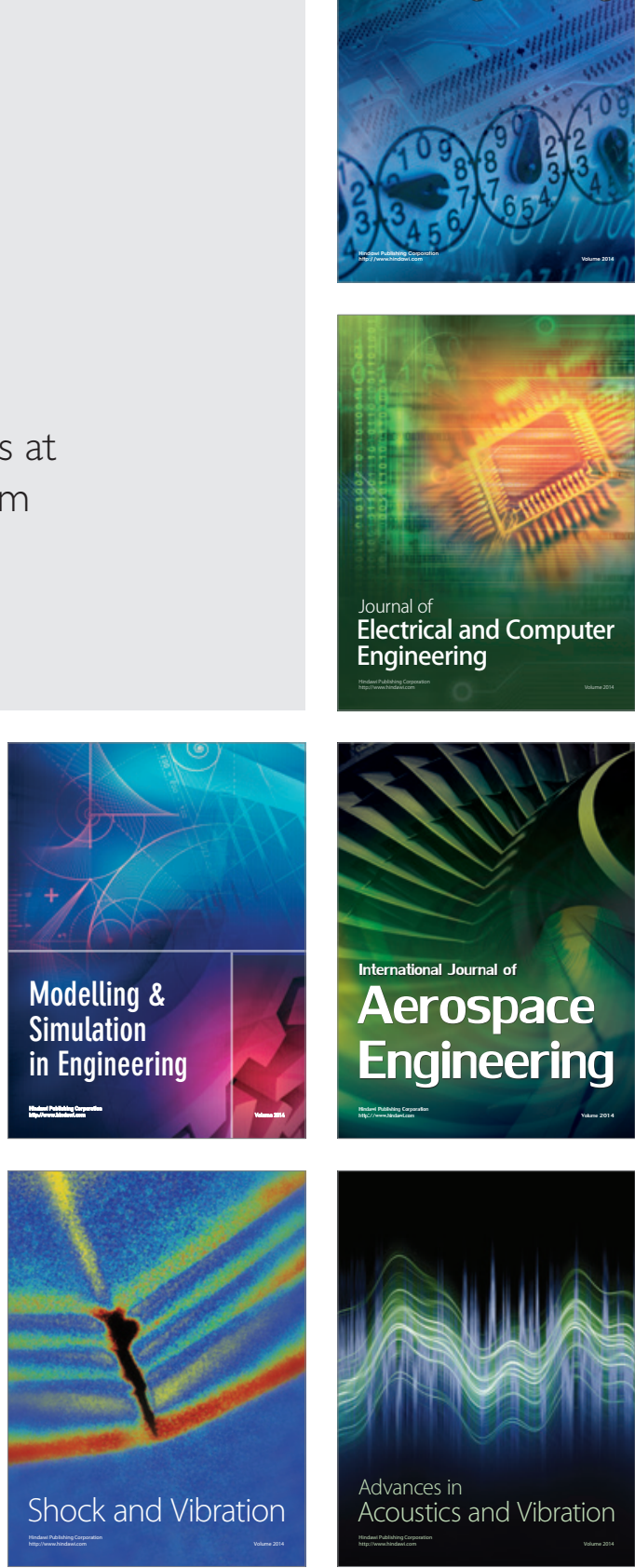